\title{
The Role of Green Infrastructures in Urban Planning for Climate Change Adaptation
}

\author{
Luisa Sturiale $^{1, * \mathbb{D}}$ and Alessandro Scuderi ${ }^{2}$ \\ 1 Department of Civil Engineering and Architecture, University of Catania, 95100 Catania, Italy \\ 2 Department of Agricultural, Food and Environment, University of Catania, 95100 Catania, Italy; \\ scuderia@unict.it \\ * Correspondence: luisa.sturiale@unict.it
}

Received: 31 July 2019; Accepted: 28 September 2019; Published: 4 October 2019

\begin{abstract}
The population that lives in cities has surpassed the one that lives in the countryside. Cities are recognized as apriority source of pollution. The degradation of air quality and the phenomenon of Urban Heat Island (UHI) are some of the most well-known consequences of urban development. The adaptation of the cities is emerging as one of the greatest challenges that urban planners will face in this century. Urban Green Infrastructures (GIs) could help cities adapt to climate change, and the strategy of expansion of greening in urban planning could play an important role in enhancing the sustainability and resilience of cities and communities. Many studies have shown the benefits of GIs to climate change mitigation and adaptation in urban areas and their role as an important urban planning tool to satisfy environmental, social, and economic needs of urban areas. The objective of this article is to propose a methodological approach to evaluate the social perception of citizens regarding urban green areas. The proposed methodology, applied to the reality of the "urban green system" of Catania, is based on an integrated approach between participatory planning and the methods social multi criteria evaluation to guiding the city's government to realize a new urban resilient development.
\end{abstract}

Keywords: urban green system; ecosystem services; climate change benefits; resilient city; urban resilient development; green urban planning

\section{Introduction}

The actions against climate change and its effects on society and the environment are oriented in two directions: Mitigation, to progressively reduce the emissions of climate-changing gases responsible for global warming, and adaptation, to reduce the vulnerability of environmental, social, and economic systems and to increase their capacity for climate resilience." Many adaptation and mitigation options can help address climate change, but no single option is sufficient by itself. Effective implementation depends on policies and cooperation at all scales and can be enhanced through integrated responses that link mitigation and adaptation with other societal objectives" [1].

The evaluation of the integrated effects of planning and planning choices aimed at reducing climate-changing emissions is a priority theme in the document "Transforming our world: The 2030 Agenda for Sustainable Development [2]". The 2030 agenda establishes 17 sustainable development goals (SDGs) and 169 targets to be achieved within the next 15 years. Goal 11, sustainable cities and communities, is specifically dedicated to urban systems, and its ambitious goal is to "make cities and human settlements inclusive, safe, resilient, and sustainable."

The percentage of people living in urban areas will increase from $50.0 \%$ in 2010 to nearly $70.0 \%$ by 2150 [3]. For the first time in history, the population that lives in cities has surpassed the one that lives in the countryside or outside the inhabited centers. The cities are recognized as the priority 
source of pollution. Most energy consumption is connected to cities, which have to make the greatest efforts to manage sustainable resources under the social, environmental, and economic aspects and to improve the quality of life of their citizens. Heat waves in cities generate serious inconveniences for the most vulnerable citizens, especially the elderly and children. Urban socio-ecological systems are characterized by a high population density, an extensive change in land use, and the use of natural resources not directly present locally. In Europe, urbanization processes are progressing rapidly, causing soil sealing and the reduction of its functions and quality. One of the major consequences of urbanization, in terms of the impact on human health and environmental quality, is the "urban heat island" (UHI) effect (the phenomenon whereby cities appear to be warmer than the surrounding rural area). It is estimated that climate change will greatly aggravate the extent of the UHI, particularly in hot regions characterized by periods of summer dryness such as the Mediterranean Basin.

Protecting, upgrading, and increasing urban and peri-urban forests and street trees through the enhancement of the green infrastructures (GIs), is therefore fundamental for the sustainable development of urban areas that represent "demand areas for Ecosystem Services, "the goods and services provided to man by nature.

The maintenance of urban green spaces is also one of the approaches suggested by the IPCC (2014) [1]. For the management of climate change risk through adaptation, in particular through the reduction of vulnerability and exposure through development, planning and practices that include "low-regret" measures, i.e. those that produce benefits even in the absence of climate change and with which the adaptation costs are relatively low compared to the benefits of the action. Lastly, the maintenance of urban green spaces is one of the approaches suggested by SDGs 11 (Sustainable Cities and Communities) of the UN Agenda to 2030 [2].

In recent thinking, the GIs have been identified as 'best practices' in local governance when combined with traditional "grey" infrastructure to achieve greater urban sustainability and resilience. Moreover, GIs are recognized for their value for adapting to the emerging and irreversible impacts of climate change. In addition, some local governments have adopted GIs as a climate change adaptation measure, particularly if the strategies result in multiple other benefits. Indeed, adaptation to climate change is also seen as having ecological, economic, and social dimensions [3].

For three out of four European citizens, climate change is a very serious problem. The changes observed in the climate are already having far-reaching repercussions on ecosystems, economic sectors, human health, and welfare in Europe. Overall, the economic losses recorded in Europe in the period 1980-2016 caused by meteorological phenomena and other extreme climate-related events exceeded Euro 436 billion. The biggest losses would be in the industrial, transport, and energy sectors (CE, COM (2018), 738 final).

The cities will have an important role to adopt the law and the provisions that are necessary at the various levels but also to ensure the best quality of life in urban areas. Climate impact requires the use of innovative solutions and the rethinking of urban management and planning [4].

New urban and territorial structures, low energy consumption buildings and infrastructures, green areas and the adoption of advanced technologies mitigate global emissions and local pollution, promote adaptation to climate change, reduce the energy costs of families and businesses, and improve the climate of cities.

GIs and their integration in urban planning appear as one of the most appropriate and effective ways to improve the microclimate and face the impacts of climate change and mainly the UHI effect. GIs forms include green roofs, green walls, urban forest, bioswales, rain gardens, urban agriculture (urban gardens; community gardening; collective green; peri-urban agriculture, agricultural parks), river parks, local products markets, areas of constructed wetlands, alternative energy farms, and nature conservation areas, among the most common (Figure 1). 


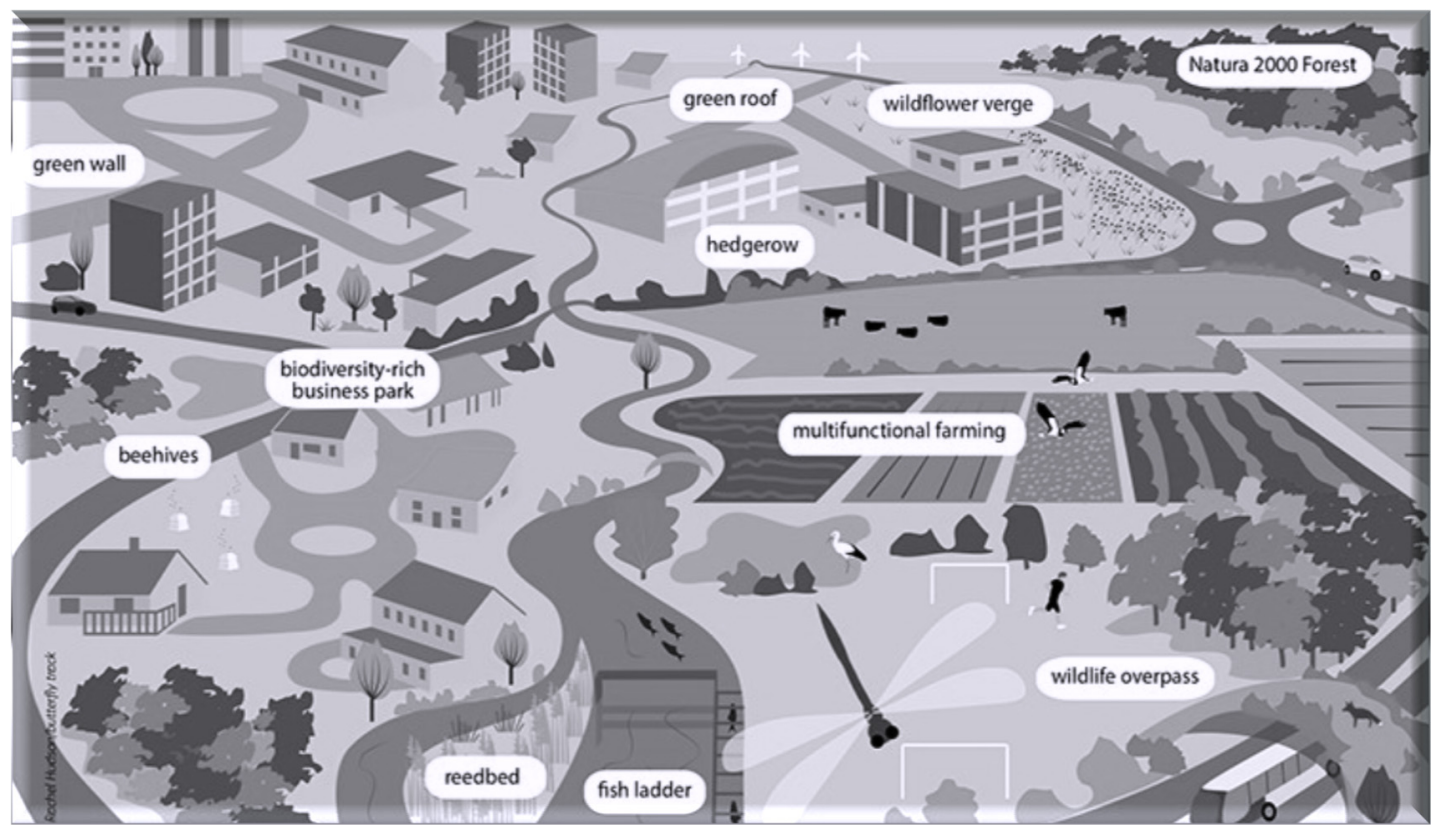

Figure 1. The different forms of Green Infrastructures (adapted from EU 2016) [5].

GIs provide a range of climate change services that can make both a substantial contribution towards adapting to climate change and a limited yet important contribution towards mitigating climate change. Such natural interventions are increasingly being recognized as a desirable 'win-win' approach to combating climate change, as they also help to deliver multiple other social, economic, and environmental benefits.

Green Infrastructures, according to the European Union (E.U.) definition, "... are networks of natural and semi-natural areas planned at strategic level with other environmental elements, designed and managed in such a way as to provide a wide spectrum of ecosystem services. This includes green (or blue, in the case of aquatic ecosystems) and other physical elements in areas on land (including coastal areas) and marine areas. On the mainland, green infrastructures are present in a rural and urban context" [6].

In the EU, the term GIs was first introduced in the 2009 commission white paper, "Adapting to Climate Change" [7]. In all the normative acts of the EU, the term "Green Infrastructures" is used in connection with landscape resources, with particular emphasis on ecological connectivity. In contrast, the European Environment Agency (EEA) and other European programs choose to use the term "green spaces," "green systems, "or "green structure" when referring to the urban environment or other related issues $[8,9]$.

The objectives of the EU GIs Strategy (2013) [6] are:

- $\quad$ To enhance, conserve, and restore biodiversity by inter alia increasing of spatial and functional connectivity between natural and semi-natural areas and improving landscape permeability and mitigating fragmentation.

- To maintain, strengthen, and, where adequate, to restore the good functioning of ecosystems in order to ensure the delivery of multiple ecosystem and cultural services.

- To acknowledge the economic value of ecosystem services and to ncreasethe value itself, by strengthening their functionality.

- To enhance the social and cultural link with nature and biodiversity, to acknowledge and increase the economic value of ecosystem services and to create incentives for local stakeholders and communities to deliver them.

- To minimize urban sprawl and its negative effects on biodiversity, ecosystem services, and human living conditions. 
- To mitigate and adapt to climate change, to increase resilience, and reduce vulnerability to natural disaster risks such as floods, water scarcity and droughts, coastal erosion, forest fires, mudslides, and avalanches as well as urban heat islands.

- To make the best use of limited land resources in Europe.

- To contribute to a healthy living, better places to live, provisioning open spaces and recreation opportunities, increasing urban-rural connections, contributing to sustainable transport systems, and strengthening the sense of community [10].

Many studies show the existence of important links between urban green and impacts on climatic conditions and the reduction of the heat island effects. Parks and trees offer shaded areas and help to cool the air, and they protect from solar radiation. The green surfaces also have a heat absorption effect and lower thermal inertia than when compared to concrete or asphalt surfaces. The integration of vegetation in the facades and on the roofs of buildings helps to balance the interior temperatures.

This article proposes a brief overview of the GIs and their benefits and their role as an important urban planning tool to satisfy different environmental, social, and economic needs of urban areas and to realize a resilient urban development. Urban resilience aims to increase the ability of the whole urban system (including physical, environmental, and socio-economic perspectives) to develop its adaptative capacity, to resist and recover from shocks and stresses, and, at the same time, to reduce its vulnerability. In this context, it becomes interesting to investigate the relationship between GIs and climate comfort within cities and the role of the urban green spaces as an essential component of the policies of mitigation and adaptation to climate change in the planning process. This is followed by the evaluation of green planning policies and adaptation measures in the city of Catania, to acquire useful information in order to guide the city government towards resilient urban planning. The methodology proposed and applied to the green areas of Catania and the planning of investments in GIs, is based on an integrated approach between participatory planning techniques (based on the establishment of focus groups with the various stakeholders) and the NAIADE method (Novel Approach to Imprecise Assessment and Decision Environments) [11] (for the Multi-Critical Social Assessment-SMCE) for the "complex" information collected (quantitative and qualitative data).

\section{The Green Infrastructures as Tools for Climate Adaptation of Cities: Experiences and Evaluations}

The relationship between city and climate change is now documented internationally by various studies, which highlight the negative effects on the well-being of the population and environmental ecosystems. The phenomena of pollution, heat islands and urban decay are now known, to name a few [12-14]. The E.U. has given a strong impetus to the fight against climate change and environmental protection. To this end, among various measures, it has promoted the European Strategy for Adaptation to Climate Change (2013) [15]. That has the objective of making Europe more resilient to climate change, promoting two types of interventions: Mitigation and adaptation.

The definition of the urban adaptation strategies actively involves citizens and other interested stakeholders to favor "non-regret" interventions that can remedy existing problems and bring immediate benefits and socio-economic benefits to increase adaptive capacity and actions based on an ecosystemic or "green" approach [4]. These actions envisaged are aimed to promote experimental interventions of climatic adaptation of public spaces and encourage the diffusion of different forms of GIs and the increase of public and private urban green areas, adopting the logic of green and blue infrastructures, and safeguarding biodiversity in urban areas.

Climate change requires the use of innovative solutions and new tools for urban management and planning. New urban structures, low energy consumption buildings and infrastructures, green areas, and the adoption of advanced technologies mitigate global emissions and local pollution, which promote adaptation to climate change. In the new vision of a city, sustainable and resilient, the green areas assume ever greater importance and become multifunctional resources for the city and its inhabitants. 
The connotation of GIs includes the green space of the complex urban ecosystem, composed of various forms of non-built spaces, including gardens, parks, vertical plants, forestry, urban gardens, agricultural land, greenways, wetlands, and waterways (green and blue infrastructures) [16-18].

The green spaces in urban areas provide indirect and direct benefits to human health and well-being, which are defined as Ecosystem Services (ESs). The ESs “... consist of the flows of matter, energy, and information coming from the stocks of natural capital, which are combined with the services of anthropogenic artifacts to generate well-being and quality of life ..." [19]; they perform the following functions: Environmental-regulator; hydrogeological protection; social, recreational and therapeutic; cultural and educational; aesthetic-architectural.

In particular, the ESs help adapt cities for climate change, through the air purification, global climate regulation, urban temperature regulation, noise reduction, and runoff mitigation. Several studies show the existence of important links between urban greening and impacts on climatic conditions: Parks and trees offer shaded areas and help to cool the air, they are places to find relief during heat waves, they offer plant cover, and they protect from solar radiation; the integration of vegetation in the facades and on the roofs of buildings helps to balance the interior temperatures as well as protect the structures [20-24].

The implementation of GIs promote an integrated approach to land management, determine the positive effects under the aspect: Economic, in the containment of some of the damages resulting from hydrogeological instability; environmental, in the fight against climate change and in restoring the quality of environmental matrices (air, water, soil); in promoting the well-being of citizens and their social relations and promoting social inclusion [4].

The benefits of the GIs are:

- $\quad$ Health and well-being: Increasing life expectancy and reducing health inequality; improving levels of physical activity and health; improving psychological health and mental well-being.

- Climate change: Heat amelioration; reducing flood risk; improving water quality; sustainable urban drainage; sustainable transport; improving air quality.

- Land regeneration: Regeneration of previously developed land; improving quality of the place; increasing environmental quality and aesthetics.

- Wildlife and habitats: Increasing habitat area; increasing populations of some protected species; increasing species movement.

- Economic growth and investments: Inward investments and job creation, land and property values; local economic regeneration.

- Stronger communities: Social interaction, inclusion, and cohesion; community engagement; education and participation; a sense of place; experiencing nature [4].

Worldwide, GIs have been spreading for at least a decade for their social and environmental benefits and as a tool for fighting climate change in urban areas. It is not possible to report the multiple experiences of projects already completed and underway, but some interesting examples will be recalled here.

In the USA, several cities have planned the development of specific GIs plans (New York, Chicago, Washington D.C.) or have foreseen their presence in the climate protection action plans (San Diego); the Greenworks Philadelphia aims to turn Philadelphia into "the greenest city in America" and includes an extensive list of GIs measures (Figure 2) [25,26]. 


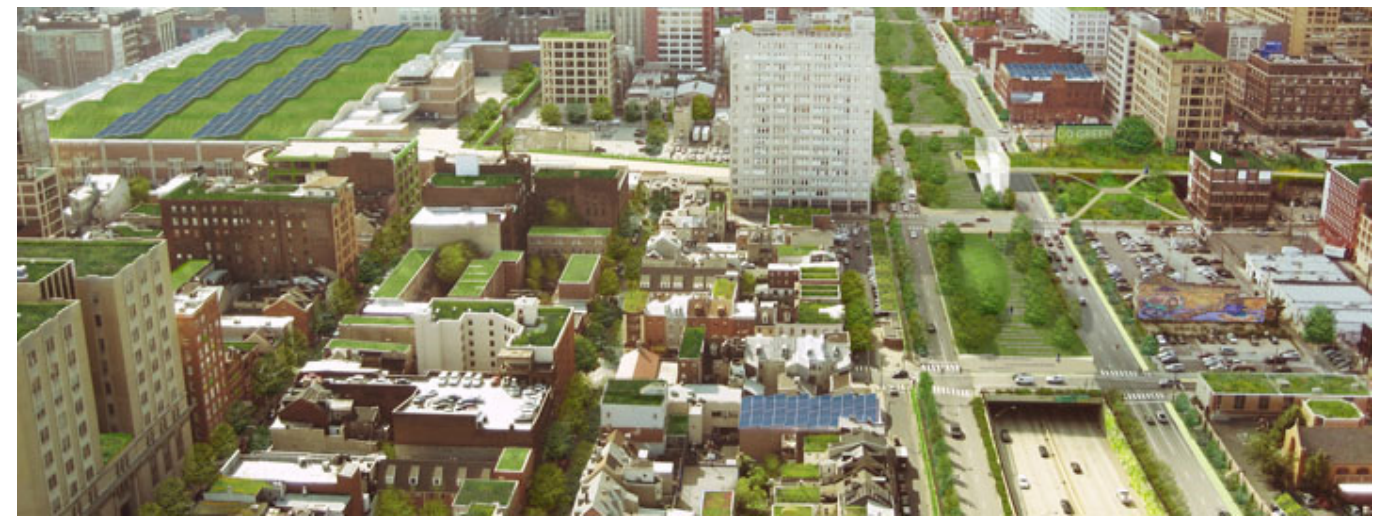

Figure 2. Green waterstorm infrastructure in Philadelphia (USA).

From northern Europe to the Mediterranean area, climate adaptation plans and experimental projects have been adopted or are being drafted for the creation of sustainable eco-neighborhoods and various GIs, in urban areas and also around cities, playing an important role in regulating urban sprawl, regulating urbanization, and the growing senseless land consumption.

Just to name a few, this is the case of the British Green Belts (in urban planning in the UK), the Anella Verda of Barcelona, which includes a network of 12 protected areas around the city connected by increasingly enhanced ecological corridors; the vertical forest in Milan (Figure 3); the Green Belt in Turin; the green ring of the municipality of Mirandola (Modena); urban gardens in Catania [27]. Other projects and studies related to the progressive insertion of the different forms of GIs in the green planning of cities are found from Europe to Asia: In Copenaghen [28], Berlin [29] (Figure 4), Hong Kong [30], Beijing [31], and the Pukou District in Nanjing [32].

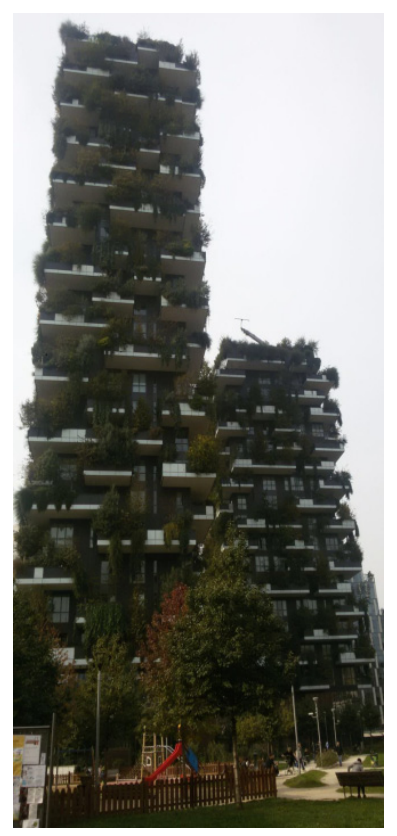

Figure 3. Vertical forest in Milan (Italy). 


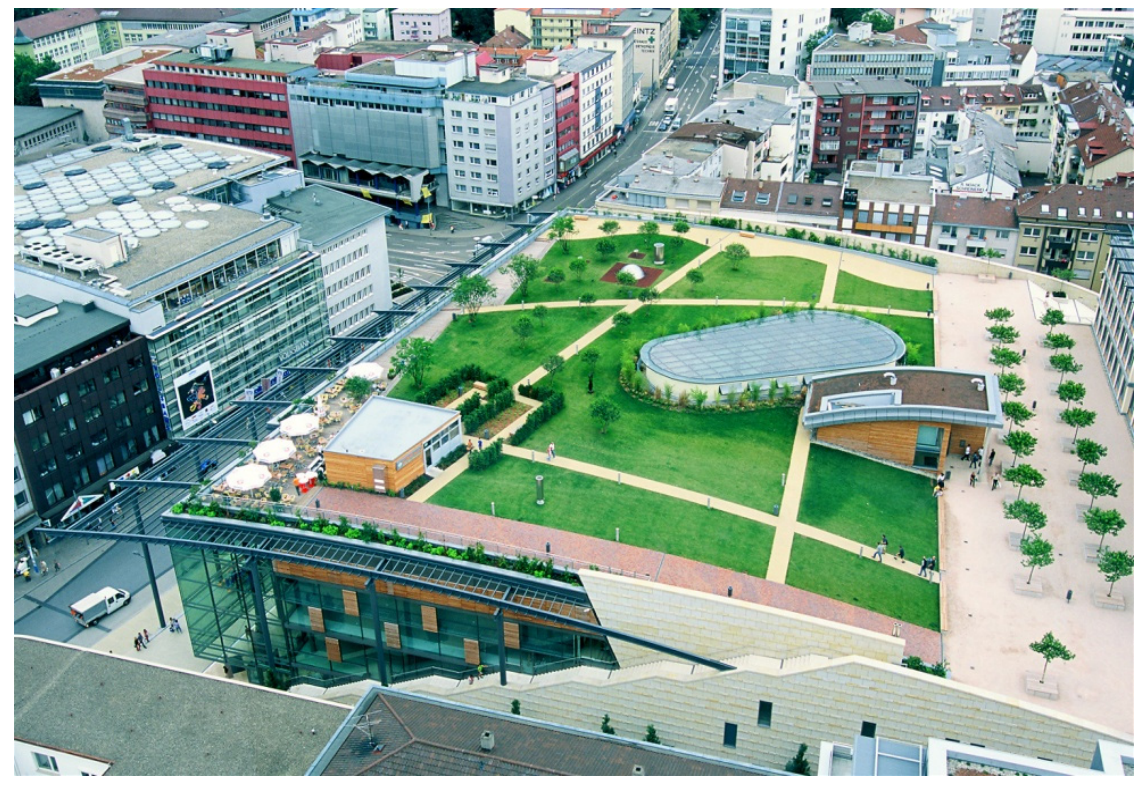

Figure 4. Germany's green roofs.

There is a large literature of specific researches that explore the important role that the GIs in urban areas play in adapting for climate change and as low-cost mitigation strategies [33-35]. Other researches place particular attention on models for evaluating ESs offered by urban GIs $[4,27,31,36]$.

GIs practices such as trees, shrubs, lawns, green roofs, and green walls have been proven efficient in reducing the urban sprawl, the UHI, the harmful air pollutants, and regulating the Green House Gas (GHG) emissions within the cities [36-39].

Based on the urban specificities, on the socio-economic and environmental aspects of the cities considered and on the types of GIs studied, the methodological approaches found in the literature are different. It is possible to identify the application of the i-Tree eco model to present output from energy exchange and hydrological models showing surface temperature and surface runoff in relation to the green infrastructure under current and future climate scenarios (in greater Manchester [40]), or to quantify in biophysical and monetary terms the ecosystem services air purification, global climate regulation, and the ecosystem disservice air pollution associated with biogenic emissions (in Barcelona [36]). Several researches have used integrated approaches recognizing the multi-functionality of GIs, highlighting both the economic aspects and social and environmental aspects (in Nanjing China, morphological spatial pattern analysis MSPA method [29]; in Catania Italy, the eco-social-green model using Social Multi Criteria Evaluation SMCE [4]) and for planning and managing urban green infrastructure for urban sustainability and resilient cities [41,42].

Municipalities are called to respond to climate problems with new governance tools to distribute the risk of impacts, which aims to involve citizens to a greater extent in the project proposals for interventions and measures. Indeed, it is important for urban governance to assess the social perception of investments in GI and to estimate the benefits of related ecosystem services. The interactions between stakeholders involved in urban projects have proved useful in different experiences but havenot yet been widely applied to climate change adaptation actions in cities [4].

The good functionality and the correct use of the public green areas require the support of multi-criteria evaluation tools and specific government tools, able to guide the administrators in the choices of planning of the green investments and management as well as to provide citizens with elements of knowledge and respect towards this important common good [43,44]. The success of a particular public green space is not solely in the hands of the architect, urban designer or townplanner; it also relies on people adopting, using, and managing the space. People make places, more than places make people $[45,46]$. 
The implementation of GIs promotes an integrated approach to land management, determines positive effects under the economic, social, and environmental aspects. The GIs become an important tool of action for climate adaptation, for the enhancement of ESs and biodiversity, and social cohesion in the model of a sustainable and resilient city of the future.

\section{The Perception of the GIs in Urban Green Planning: The Case Study of Catania}

In Italy, the GIs are still few, limited to individual local initiatives and in any case, are not included in system logic, which essential for achieving the objectives. The attention to the presence of green in urban areas, in its various forms and functions, has been growing in recent years, so much so that even at the regulatory level several laws have been promulgated on the subject. Among them, the Law on the 14 January2013, n. 10 rules for the development of urban green spaces, in which the functions of urban green are recognized:

- Ecosystem services: Positive effects on the local climate, on air quality, on noise levels, and soil stability are evident, biodiversity conservation

- Socio-economic aspects: Meet the needs for recreation, social relations, cultural and healthy growth of its inhabitants.

Despite the multiple benefits associated with green, the Italian situation still shows some critical issues. Urban green is mainly managed on a technical and prescriptive level rather than as a strategic resource to orient local development policies to quality and resilience [4].

The city of Catania is the second city, in terms of importance, surfaces, and inhabitants of the Sicily Region (180,000 square meters, about 350,000 inhabitants, a density of 1.7 inhabitants per square meter). Under the urbanistic aspect, the regulatory plan, drawn up in 1964, was designed for the socio-economic needs of the city of the $60 \mathrm{~s}$, where the priorities and the vision were completely different from the current ones, mainly in terms of environmental protection, attention to climate change, and social inclusion. Concerning the socio-economic development of Catania, for the future potential of the urban green areas, the municipal administration has planned a program of interventions in line with climate adaptation measures [47-49]. The known negative impacts of climate change are also recorded in Catania, and some indicators are shown in the following figures (Figures 5 and 6)

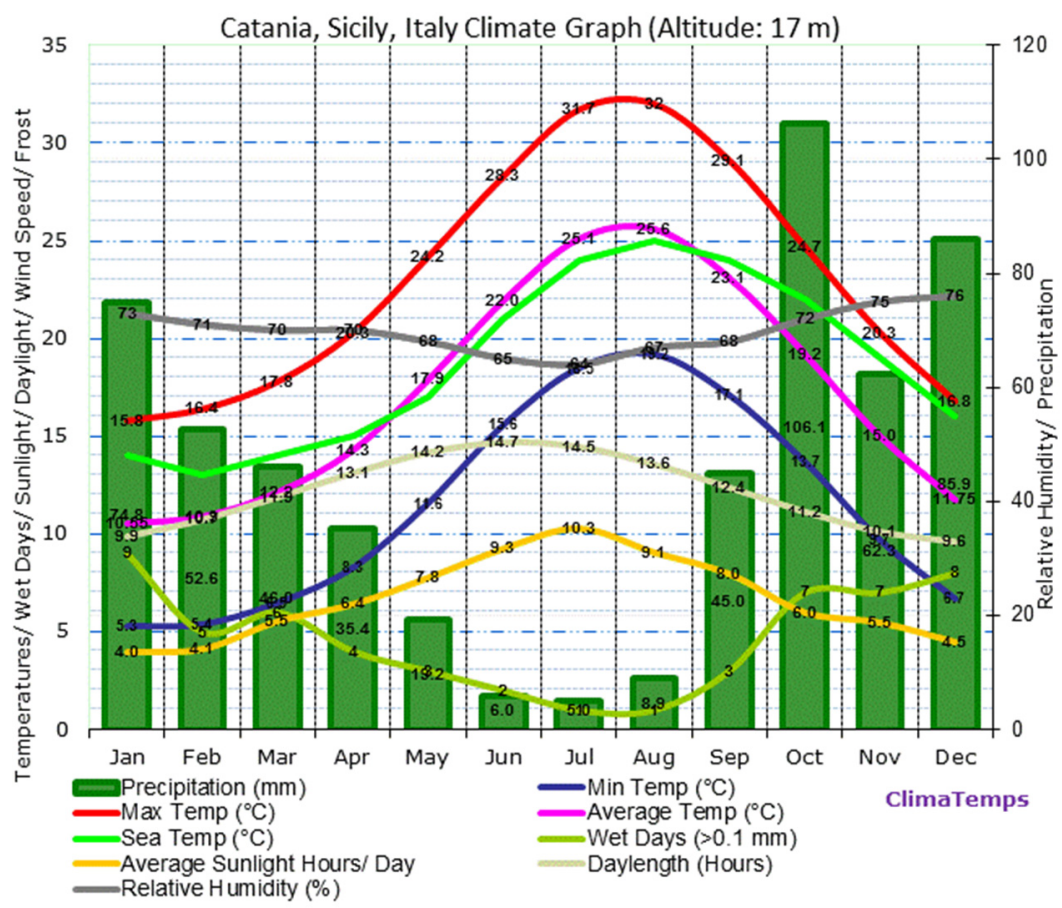

Figure 5. Trend of main climate indicators of the city of Catania (monthly averages). 


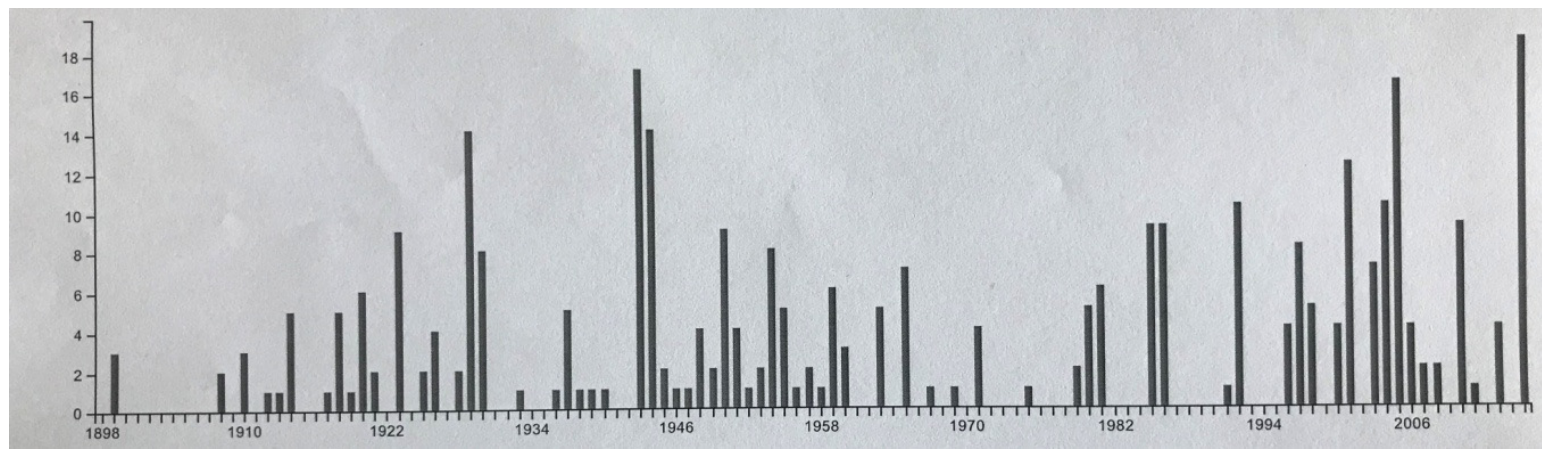

Figure 6. The hottest days in a year in Catania from 1900 to today.

The main climate indicators of Catania are indicated in Figure 5 and the climate trends from 1900 to the present in the area of Catania, analyzing the meteorological data (www.lab.gedidigital.it), it can be summarized as follows:

- The average temperature in the area between 2000 and 2017 was $0.6679{ }^{\circ} \mathrm{C}$ above the $20^{\text {th }}$-century average;

- The number of hot days (above $29^{\circ} \mathrm{C}$ during $24 \mathrm{~h}$ on average) increased from 2.35 days per year in the $20^{\text {th }}$-century to 5.222 per year from 2000 onwards (Figure 6); the number of frost days (below $-1{ }^{\circ} \mathrm{C}$ for $24 \mathrm{~h}$ on average 24 ) remained unchanged at zero days per year.

The municipality of Catania is in the process of defining their adaptation plan. However, the city has already started a series of adaptation measures, including the planning and implementation of GIs and oriented management of public green areas.

In the city of Catania (Kmsq 183), the extension of the urban green is equal to $4,843,660$ square meters, and the urban green per inhabitant corresponds to 16.4 square meters.

The scenario of the urban green spaces in Cataniais shown in Table 1:

Table 1. The urban green spaces of the city of Catania $\left.{ }^{*}\right)$.

\begin{tabular}{lc}
\hline Green Typology & Square Metres \\
\hline Urban Parks (> 8,000 square metres) & 513,577 \\
Green equipment (<8.000 square metres) & 431,270 \\
Urban Design Areas & 715,500 \\
Urban Forestation & - \\
School Gardens & 350,000 \\
Botanical Gardens and Vivai & 20,000 \\
Zoological Gardens & - \\
Cemetery & 50,000 \\
Urban Gardens (mainly managed by families) & 2,500 \\
Sports areas/Outdoor play & 100,000 \\
Bosch areas (> 500 square metres) & 972,769 \\
Uncultivated Green & $1,668,044$ \\
Total Urban Green & $4,843,660$ \\
\hline
\end{tabular}

${ }^{*}$ ) Source: Directorate for Environmental and Green Policies and Energy Management of the Autoparco-Service for the Protection and Management of Public Green, Giardino Bellini and Parchi, 2019.

The green areas play an important and specific role both as an urban component for the conservation and improvement of the landscape and the environment and as a means for aggregative purposes for social and cultural integration.

The GIs should pursue the following objectives among the ones envisaged:

- Improving and preserving the local landscape and environmental restoration;

- Favor urban climate control and reduction of albedo and heat islands; 
- Increase the naturalness and biodiversity of the urban territory;

- To stimulate the aggregative, social and therapeutic functions of green areas (e.g., urban gardens, neighborhood parks, healing gardens, spaces for cultural events and shows) (Regulation of the public and private Green of the city of Catania, 2017).

The strategy for the GIs interventions includes the creation of green areas, green avenues, wetlands, and urban gardens according to the classification: Wedges, vortices, margins, strips, islands, hot points, hubs, fences, spurs, and vectors (Figure 7).

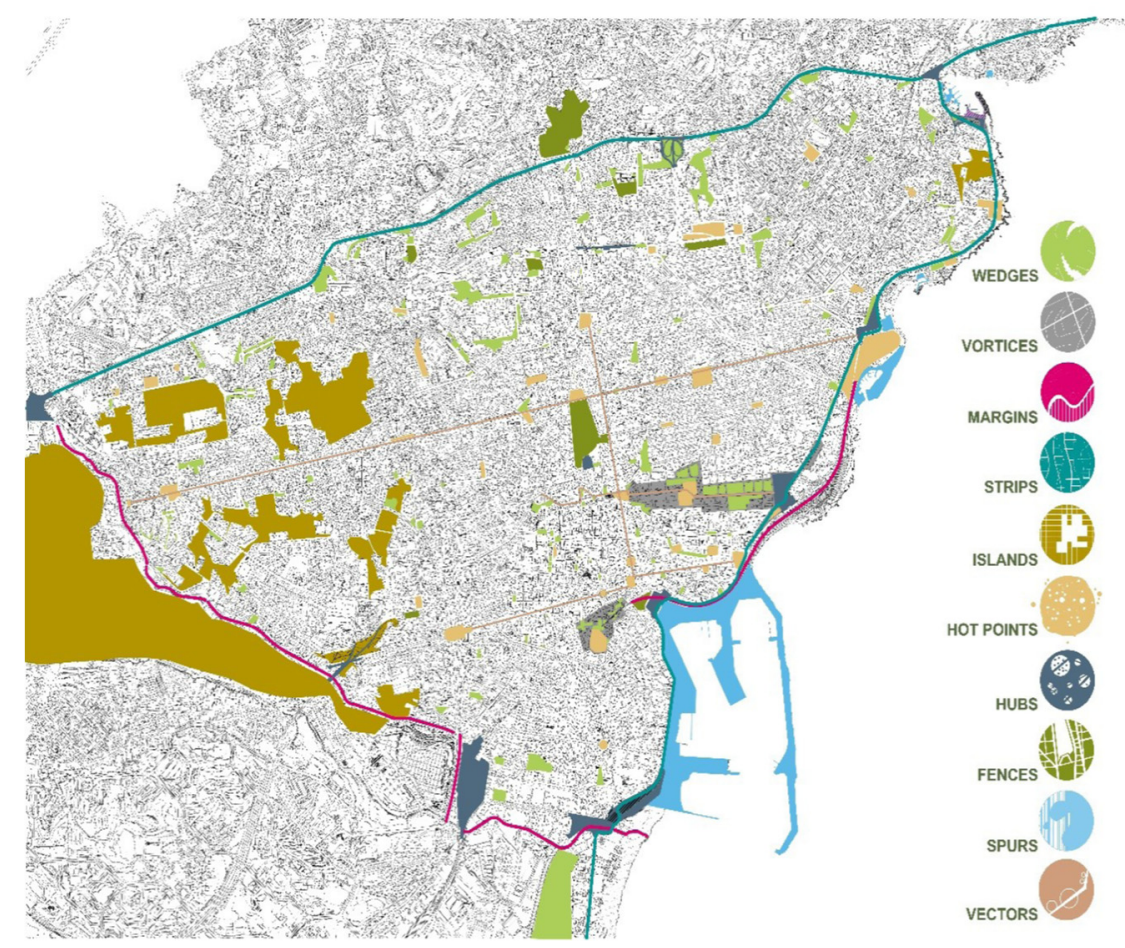

Figure 7. The types of green infrastructures foreseen in the municipality of Catania (2017).

Wedges: Urban areas with the aim of becoming green areas dedicated to developing the relationship between citizen and city. Vortices: Model of areas designed to interact with the city with an inaccurate destination (areas that can adapt to the different needs of different groups of society). Margins: Represent a bit of a breakthrough, as the boundary criterion of the city is redefined, moving it ever more towards the areas that assume a strategic significance under the aspect of livability (sea, river, park, etc.). In this vision of development, the synergies between the oriented reserve of the Simeto Oasis, Etna Park, and in general with the urban parks (Playa del Bosco, Gioeni Park, etc.) and the city are included. Strips: Areas dedicated to the connection between the different areas of Catania, also with the redefinition of the above-mentioned margins. Island areas allow the giving back to the territory its centrality, where man has included the buildings over the years. Hot spots are red areas, under the cultural, economic, and social aspects in which the interests of a large part of society are concentrated and in which a mitigating action is needed to improve the quality of the environment. This represents the areas where resident population flows, tourists, and populations that gravitates around the city with both structural and infrastructural needs. In these areas, the need for both congestion and pollution generated to create buffer areas to mitigate the effects of the hubs present in the area emerges. Spurs are the areas that correspond with the Waterfront project, which start from the port and end up in Ognina, where the city encourages the development of a tourist town on the sea. Fences: All the defined and delimited green parks are included. Vectors include the areas that represent the main routes of the city's traffic. 
The municipality of Catania has realized some GIs and others are in the course of realization, as reported in Figures 8-13 that testify the situation of the interested area before and after the realization of the GI.

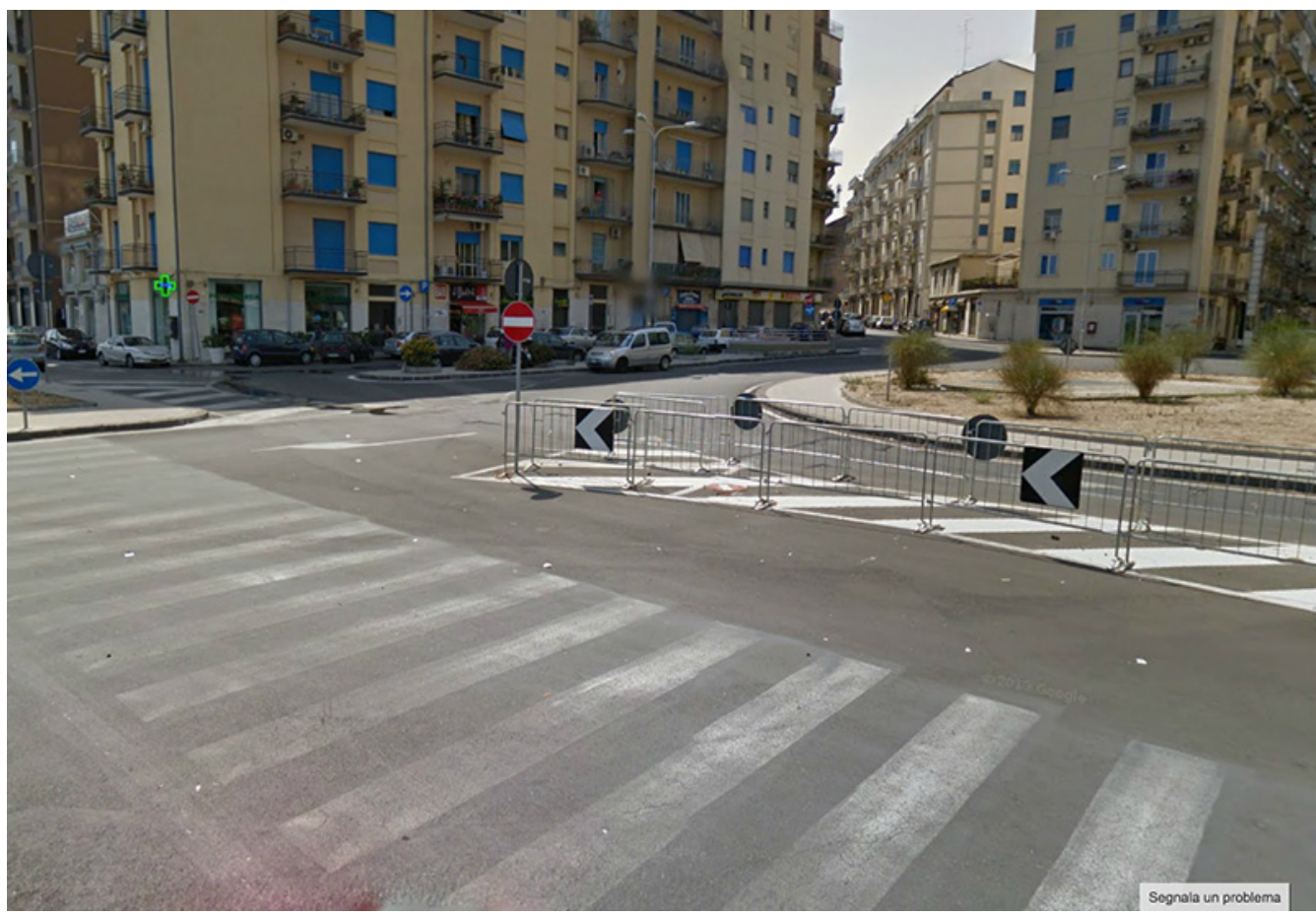

Figure 8. Piazza Galatea - Catania (before).

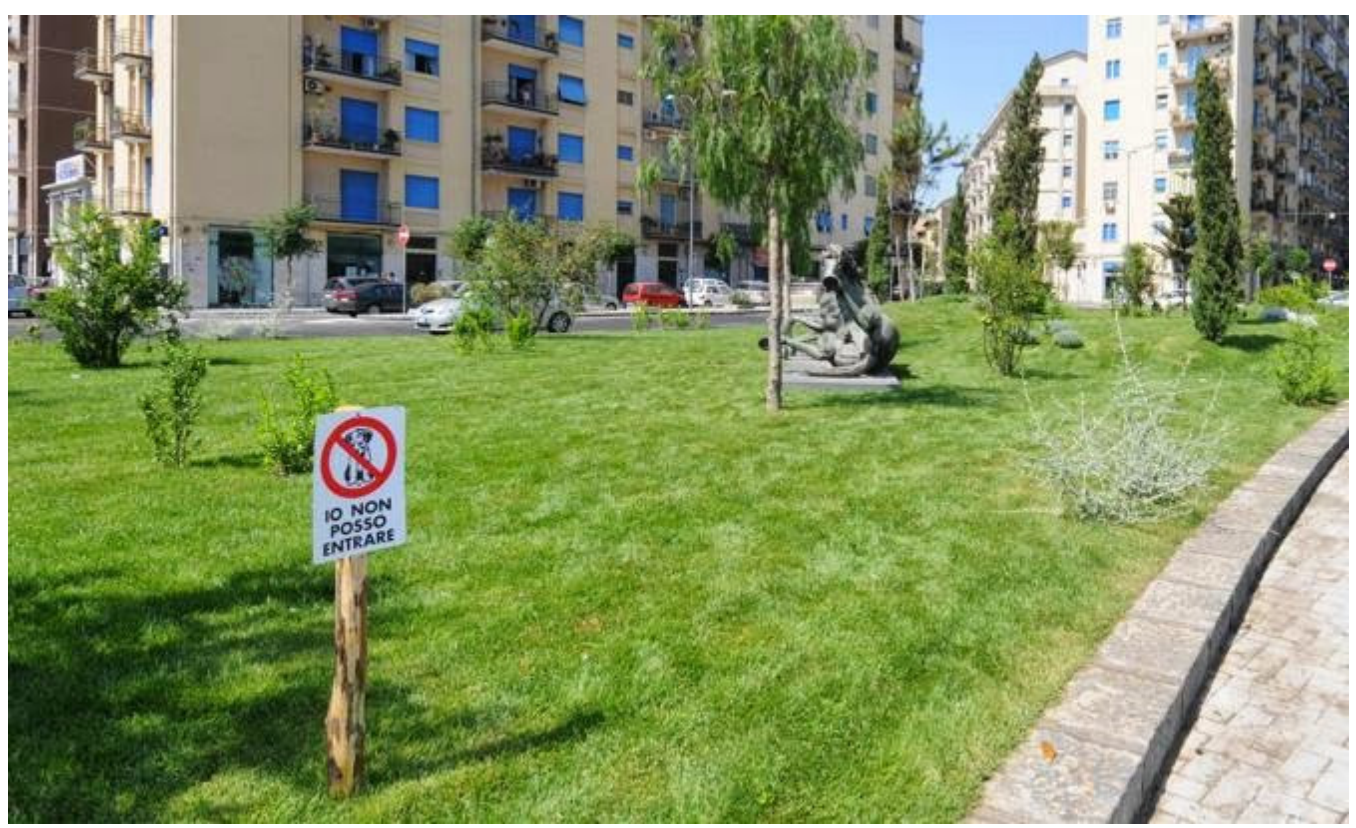

Figure 9. Piazza Galatea-Catania (today). 


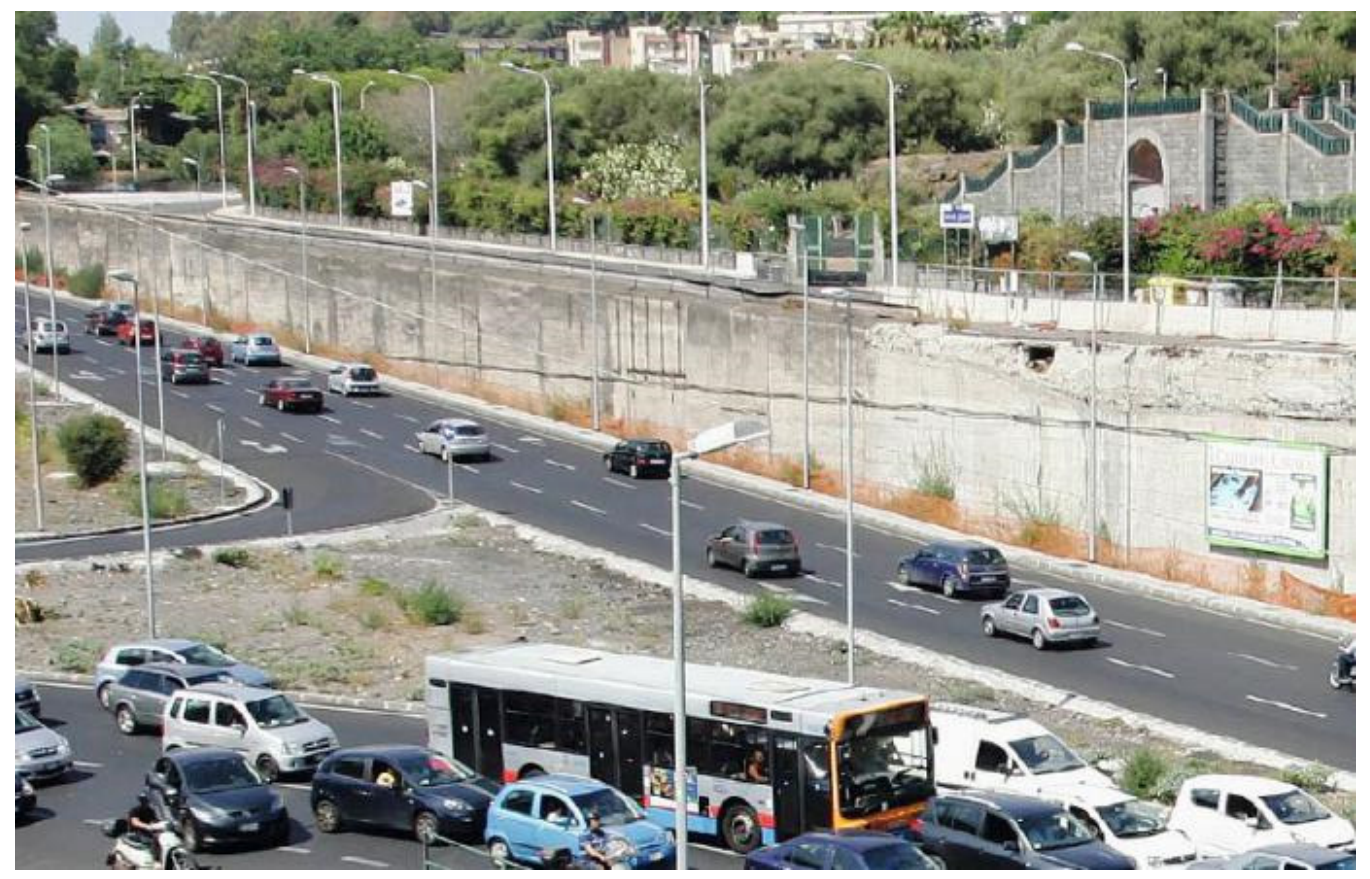

Figure 10. Tondo Gioeni-Catania (before).

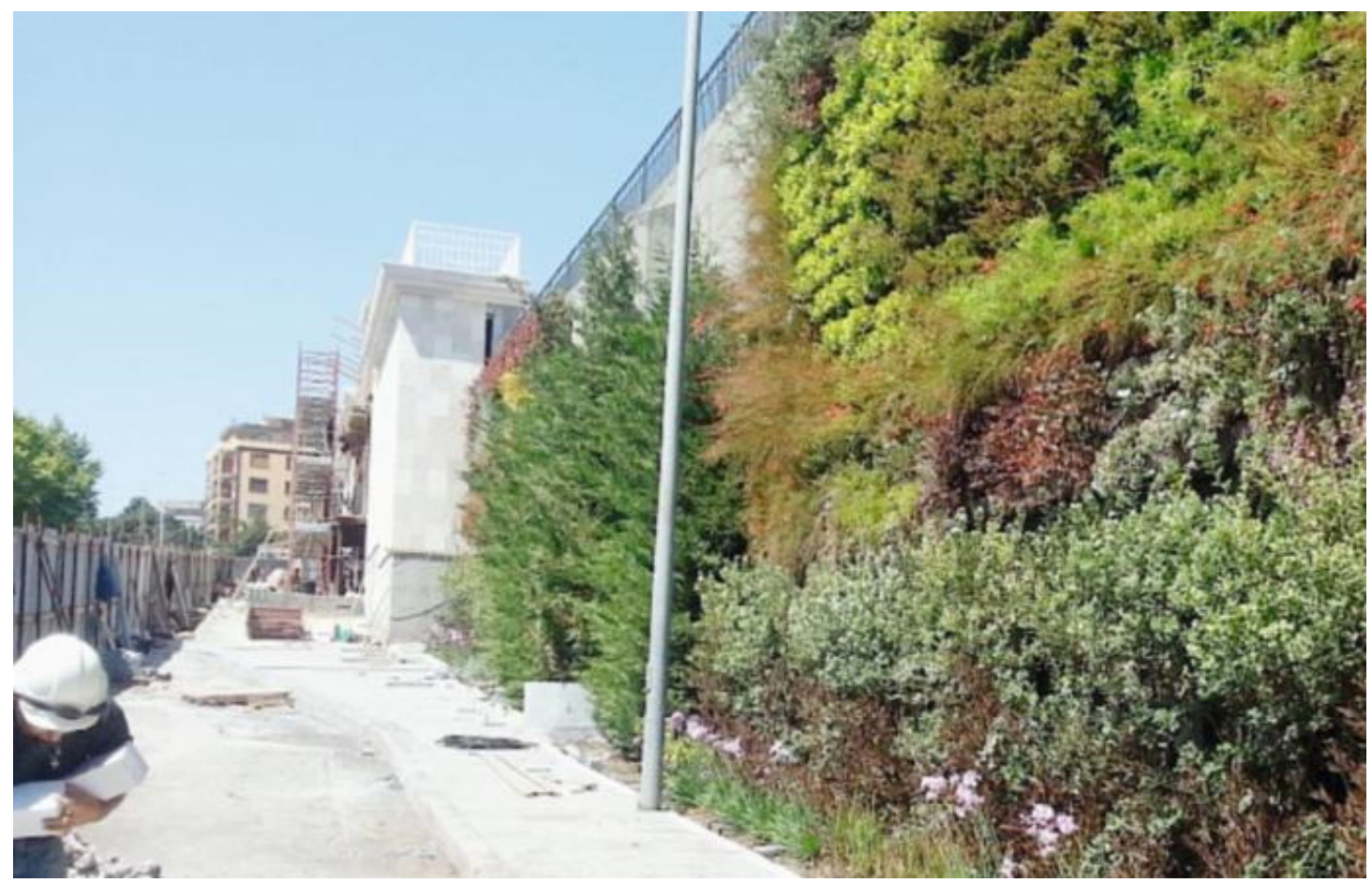

Figure 11. Tondo Gioeni (today, after the realization of the vertical wall). 


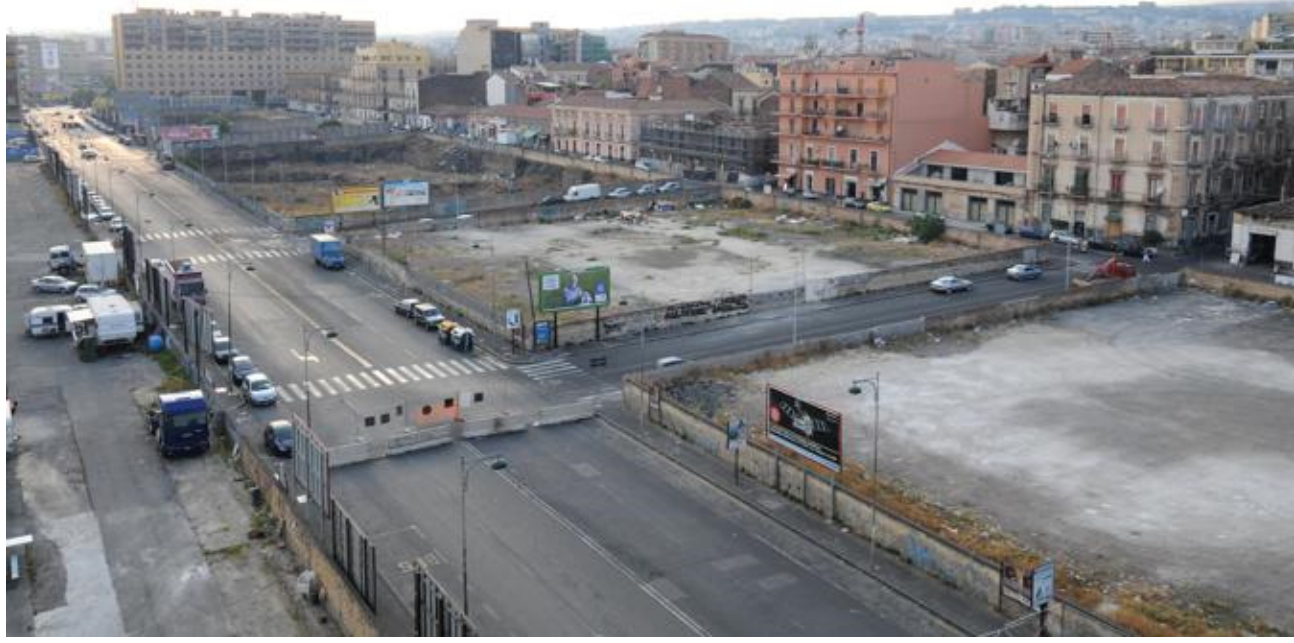

Figure 12. Corso Martiri della libertà-Catania (before).

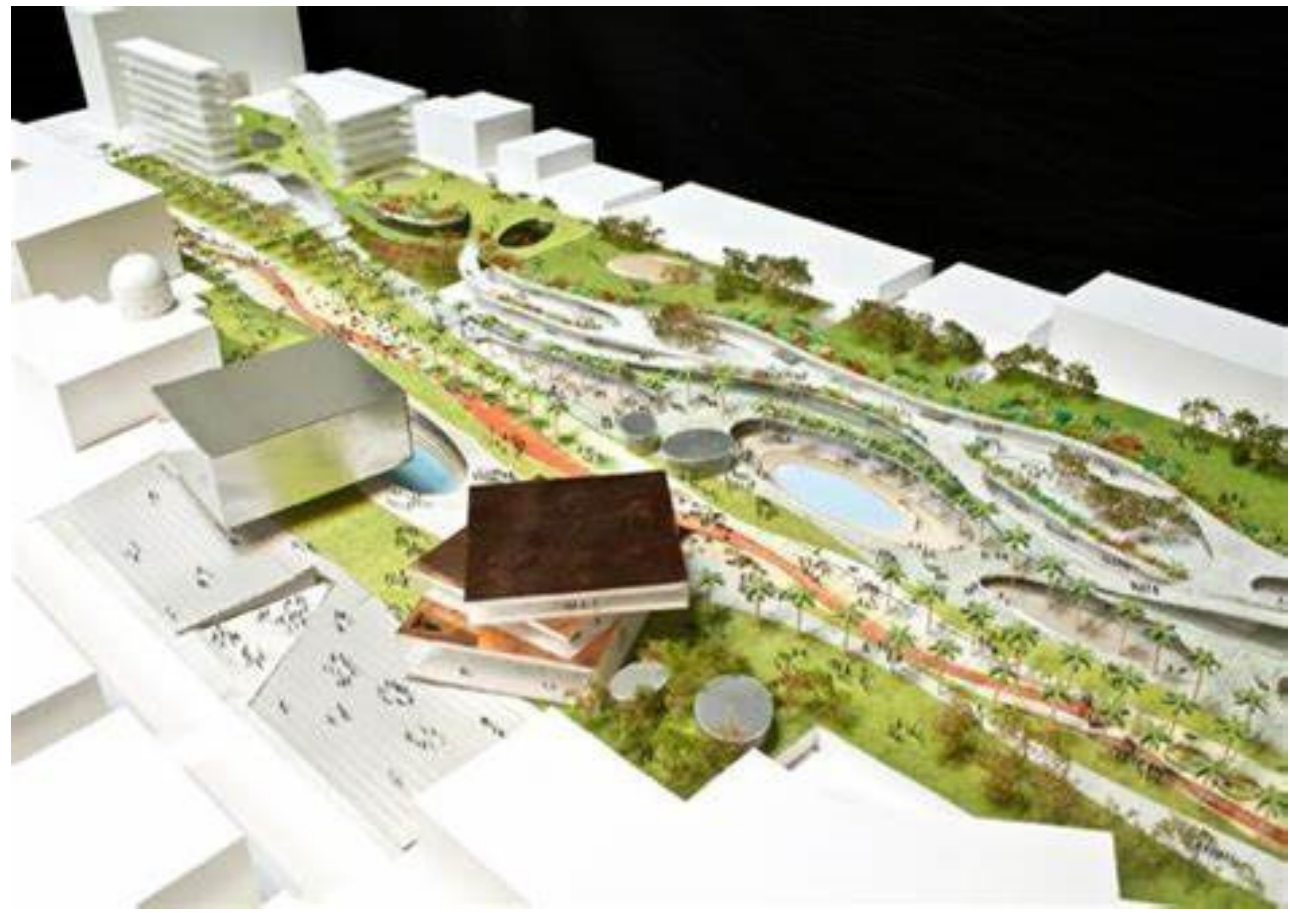

Figure 13. Corso Martiri della Libertà (project in progress).

The urban green is a heritage of the complex city, which requires careful assessment that takes into account not only the economic variables but also the social, environmental, and institutional ones. The proposals for investments in GIs, their management, and the evaluation of benefits will have to be shared by the community for an effective pursuit of the objectives set. This is an assessment that considers the dimensions of sustainable development, which will contribute to providing useful elements for the promotion of a model of governance of the city "eco-social-green" [4].

Based on the eco-social-green model, it will be possible to carry out a social, environmental, and economic assessment of the proposed interventions, through a collaborative process and by sharing 
the objectives of valorization, transformation, and redefinition of the green spaces of the city of Catania. The model proposed is called "eco-social-green" because we have decided to integrate the aspects that we consider important for the new role attributed to cities. Both at a European level and in the scientific debate, there is increasing attention on the role that cities must have on climate change, biodiversity, conservation, and promotion of social cohesion. A multidimensional approach allows to make decisions in complex conditions, and it gives the possibility to consider economic and non-economic dimensions; the existing synergies and possible conflicts, and the different viewpoints of the subjects involved (public and private).

The attention of the citizens of Catania towards the environment and the presence of greening in the city has recently increased. In fact, the initiatives of "adoption of public green" by private individuals are multiplying (to date, the public green areas of Catania adopted by private individuals, for redevelopment and maintenance, are around 4000 square metres-with savings for municipal management of around 300,000 euros). Citizens are aware that the GIs perform important functions to improve the quality of urban life, both in environmental and social terms and in terms of adaptation to climate change.

\section{Methodology}

The analysis of the case study evaluated the GIs planning of the metropolitan city of Catania, to experiment with new approaches and opportunities for the definition of green strategies that have found concrete applications in the development of guidelines in politics and local planning tools, as a tool for climate mitigation in an urban environment.

The proposed approach was based on the integration between the participatory planning (based on the establishment of the Focus Groups with the various stakeholders) and the NAIADE method (Novel Approach to Imprecise Assessment and Decision Environments [11], for the Multi-Criteria Social Assessment-SMCE) as possible a methodological structure to acquire and evaluate the "complex" information collected (quantitative and qualitative data) on possible alternative scenarios in relation to the urban green spaces.

The methodology can be considered a social experiment, able to produce collective opinions, to detect communication barriers, to study conflictual behavior, to acquire local information, and to create acceptable options [50-53].

The innovative advantage is the interaction among the participants that highlight the fundamental tools to support a process of evaluation and reciprocal learning. This approach allows us to reveal new visions of the subjects involved in order to have a final participated decision.

The target is that of developing a methodological structure made by suitable tools to acquire first, and process second, qualitative and quantitative information concerning the possible alternative scenarios of the problem under study. Opinions were collected at specific meetings at the local level with stakeholders and sector's operators involved in the issue from environmental, social, climate, landscape, health safety, and economic points of view.

The opinions were collected through specific Focus Groups with local stakeholders, operators, and citizens interested in the issue in question from different economic, social, and environmental aspects [54]. This was in the presence of 2researchers, one with the role of moderator and the other with the detector of the responses of the individual subjects involved.

The adoption of this approach was limited to problems of territorial planning referable to SMCE [55-57]. There were numerous articles that employed SMCE for the resolution of problems related to the management of environmental resources, and in general, to valuations of sustainability, climate adaptation, energy policy, etc. [58-61].

The following picture (Figure 14) identifies the steps on which our SMCE was based, with some adaptation concerning the specificity of the context surveyed. 


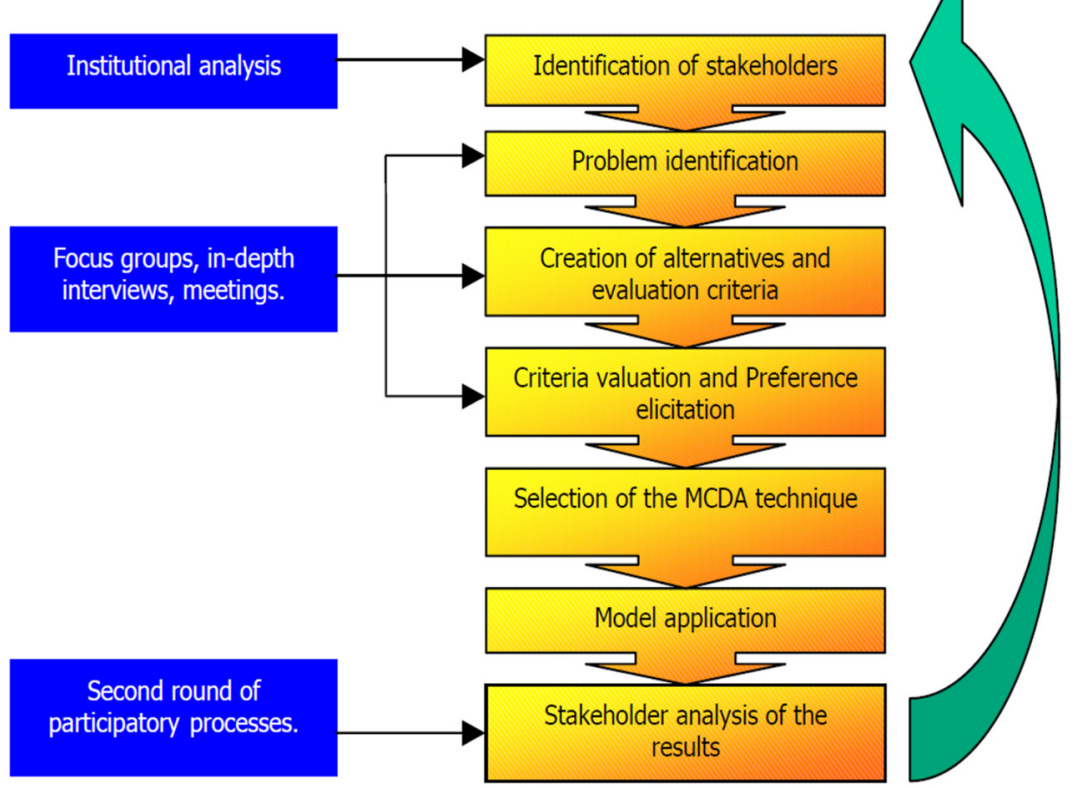

Figure 14. Structure of the model Multi-Critical Social Assessment (SMCE) [4].

In detail, the proposed model was based on:

- The individualization of the citizens and the stakeholders involved (100 questionnaires);

- The definition of the alternative scenarios (definition of the 3hypotheses of the scenario: Inclusive, resilient, and city);

- The definition of the context of evaluation, namely the decisional criteria (urban green spaces of Catania for the shared project);

- The evaluation of the impact of alternative scenarios relative to the criteria in question);

- The final creation of the impact matrix;

The structure used the focus groups as a social research methodology, aimed toacquire information on the opinions of stakeholders regarding a variety of scenarios for future development within the zone examined. The choice of focus groups and, therefore, of the interaction among the actors involved, aimed to support the phase of the choice and evaluation of the different aspects that would be included in the equity matrix. The matrices of impact and equity constituted the basis for the use of the discrete multicriteria evaluation NAIADE model (Novel Approach to Imprecise Assessment and Decision Environments) [62], able to manage qualitative and quantitative data in order to evaluate the measures of intervention. This instrument supported the classification of the alternative scenarios proposed based on the determined decisional criteria and considerations of possible "alliances" and "conflicts" between the groups of stakeholders on the proposed scenarios, thus measuring their acceptability. The NAIADE multicriteria evaluation method applied to this study constituted a discrete method of evaluation capable of managing qualitative and quantitative data. It was an appropriate tool for the planning of problems characterized by great "uncertainty" and "complexity" regarding existing territorial, social, and economic structures and their interrelations [63]. The basic input in the NAIADE method consisted of alternative scenarios to be analyzed, different decisional criteria for their evaluation, and different stakeholders who expressed opinions about the scenarios in question. One of the strengths of this tool in the application to the planning of interventions on green spaces was based on its ability to collect the conflicting perspectives of the stakeholders and to address the compromises among the environmental, social, and economic dimensions. 
Concerning the objective of this study, the analysis will be applied to the principal priorities, the methodology used for the definition of the model of management for the green area of Catania, which is the area of investigation for this work.

The evaluation through the Focus Groups was divided into 3phases, referring in the specific case to the destination of urban areas in a degraded state to be valorized:

Phase 1-consisted of "planning" the meetings. During this phase, the following were established:

- The number of sessions and the time dedicated to each of them $(8$, as an expression of the individual categories considered: Association of citizens, groups of pensioners, cultural associations, playrooms, trade unions, public institutions, scientific groups, tertiary sector's companies, with time varying from 4 to $8 \mathrm{~h}$ );

- The creation of an interview guide to conduct the discussion (scientific and dissemination materials, research papers, photos, maps, relative the problems of urban green areas and on the social, climatic effects deriving from them);

- Selection of participants (stratified selection for homogeneous groups: Age, gender, income).

The questionnaire used for the interviews was designed to explore the perception of environmental issues in the urban context and to evaluate the real needs of the population in terms of environmental quality, perception of climate change, and fruition of public green spaces. It was structured in 10 questions in order to collect information and opinions useful for the research, on the 3hypotheses proposed: Inclusive, resilient, and city.

Phase 2-consisted of "carrying out" the entire activity, based on the guide to the pre-established interview. It began with the presentation of the topic relating specifically to the action strategy for the management of degraded areas to be recovered, using the support material (articles, results, photographs), prepared specifically to introduce the issue under consideration and stimulate discussion and the interaction of the participants. During this phase, various ideas and opinions were acquired that represented the reactions of the participants involved in the issues raised.

Phase 3-consisted in the elaboration of the "qualitative results" and the production of the final report.

In this regard, various qualitative analysis tools were used, based on intentionally prepared inputs and specific rules. Overall, the Focus Groups can be considered a social experiment, able to produce collective opinions, reveal communication barriers, study conflicting behavior, acquire local information, create acceptable options, synthesize information, etc. The key advantage of the Focus Group dedicated to defining the intervention strategies in green urban areas to be enhanced, when compared to other participatory techniques, lay in the deep interaction between the participants, becoming a "social network."The participants became fundamental tools to support a "mutual learning process" on the questions examined. This participatory comparison technique made it possible to reveal new dimensions of the issue under discussion, thus underlining the possibility for the Focus Group to bring out the opinions in this regard rather than produce generalized results. The analysis phase of the results of the Focus Groups was followed by the multi-criteria analysis where the basic input of the NAIADE method consisted of alternative scenarios to be analyzed, different decision criteria for the relative evaluation, and different stakeholders that expressed opinions on the scenarios in question. Based on this method, 2 types of analysis can be performed:

A multi-criteria analysis based on the impact matrix, which leads to the definition of the priorities of alternative scenarios regarding certain decision-making criteria;

- $\quad$ An analysis of equity based on the equity matrix, which analyzes possible "alliances" or "conflicts" among different interests in relation to the scenarios in question.

In this regard, the multicriteria analysis, according to the NAIADE methodology, aimed to classify alternative scenarios based on the preferences of individual groups based on certain decision criteria [64-67]. 
The basic input of the NAIADE method was constituted by the impact matrix (criteria/alternative matrix), including scores that can take the following forms: Crisp numbers, stochastic elements, fuzzy elements, and linguistic elements (such as "very poor", "poor", "good", "very good", "excellent") [18]. When comparing alternative scenarios, the concept of distance was introduced. In the presence of crisp numbers, the distance between the 2alternative scenarios with respect to the given evaluation criterion was calculated by subtracting the respective crisp numbers.

The classification of alternative scenarios was based on data from the impact matrix, used for:

- Comparison of everysingle pair of alternatives for all the evaluation criteria considered;

- Calculation of a credibility index for each of the aforementioned comparisons, that measured the credibility of one preference relation "... alternative scenario" a "is better/worse, etc., alternative scenario «b» ... "(preference relationships were used);

- $\quad$ Aggregation of the credibility indices produced during the previous stage leading to a preference intensity index $\mu^{*}(a, b)$ of an alternative «a» with respect to another «b» for all the evaluation criteria, associated with the concept of entropy $\mathrm{H}^{*}(\mathrm{a}, \mathrm{b})$, as an indication of the variation in the credibility indices;

- Classification of alternative scenarios based on previous information.

The final classification of the alternatives was the result (intersection) of 2 different classifications: the classification $\Phi+$ (a) based on the "best" and "decidedly better" preference relationships; and the classification $\Phi-(b)$, which was based on the "worst" and "decidedly worse" preference relationships.

In relation to the objective of the present study, the analysis will be applied to the main priorities, for the evaluation of the optimal management model for the enhancement of the green areas of Catania.

\section{Results and Discussion}

The results of the present work provide a further multidisciplinary contribution to research on the management and planning of green areas in cities. Specifically, the analysis was conducted on the basis of the following question:

What are the strategies for the enhancement of urban green spaces of the City of Catania for climate change adaptation?

Three hypotheses of green recreate strategies were envisaged (Table 1):

Hypothesis 1. INCLUSIVE: Creation of green areas with inclusive and social functions (equipped parks, urban gardens, etc.).

Hypothesis 2. RESILIENT: Creation of urban green areas with non-usable landscape function but as a climate change adaptation measure.

Hypothesis 3. CITY: Conservative recovery, cleaning, and maintenance of the current green.

In order to evaluate the three hypotheses mentioned above, evaluation criteria have been defined, which represent "... a measurable aspect of the judgment that can characterize a dimension of the various choices that are taken into consideration" [68]. In the present case study, twenty evaluation criteria or variables were used. These criteria were defined based on the purpose and objectives of the evaluation of the analyzed case, which can be considered representative of the reality of the City of Catania but overall very similar to other metropolitan areas.

The objectives of the evaluation activity were environmental, social, climate, economic, landscaping, and health and safety.

Specifically, for each objective, the related evaluation criteria are considered and are indicated in Table 2. 
Table 2. The objectives and evaluation criteria adopted in the applied model for the urban green areas of Catania.

\begin{tabular}{cc}
\hline Goals & Evaluation Criteria \\
\hline Environmental & air quality; human settlement \\
Social & usability, multi-functionality, agricultural production, employment commitment \\
Climate & reduction of temperatures, creation of accessible shade areas, thermal excursion \\
Economic & cost of realization, the value of the properties; productive exploitation \\
Landscape & quality of the landscape, the exaltation of the seasons, biodiversity \\
Health safety & pollution, pathogenic presence, use of pesticides and fertilizers \\
\hline
\end{tabular}

Source: Our elaboration, data collected direct survey.

According to the above-reported indicators, impact matrix results, as a whole, are reported in the following Table 3.

Table 3. Evaluation of the results of the impact matrix of the various alternatives.

\begin{tabular}{|c|c|c|c|}
\hline Criteria of Evaluation & Scenario Inclusive & Scenario Resilient & Scenario City \\
\hline \multicolumn{4}{|l|}{ Environmental } \\
\hline Air quality & Good & Very good & Poor \\
\hline Smell emanation & Good & Excellent & Good \\
\hline Anthropization & Poor & Very good & Very good \\
\hline Waste of water & Poor & Good & Excellent \\
\hline \multicolumn{4}{|l|}{ Social } \\
\hline Usability & Excellent & Medium & Poor \\
\hline Multifunctional & Excellent & Very good & Good \\
\hline Agricultural production & Very good & Poor & Poor \\
\hline Occupational commitment & Very good & Good & Poor \\
\hline \multicolumn{4}{|l|}{ Climate } \\
\hline Temperature reduction & Good & Excellent & Very good \\
\hline Creation of shaded areas & Good & Very good & Good \\
\hline Temperature range & Good & Very good & Poor \\
\hline Humidity & Very good & Good & Poor \\
\hline \multicolumn{4}{|l|}{ Economic } \\
\hline Cost of realization & Good & Poor & Very good \\
\hline Value of real estate & Very good & Excellent & Good \\
\hline Productive exploitation & Very good & Good & Poor \\
\hline \multicolumn{4}{|l|}{ Landscape } \\
\hline Landscape quality & Good & Excellent & Good \\
\hline Exaltation of the seasons & Excellent & Very good & Poor \\
\hline Biodiversity & Excellent & Very good & Poor \\
\hline \multicolumn{4}{|l|}{ Health Safety } \\
\hline Pollution & Good & Very good & Good \\
\hline Presence of pathogens & Poor & Good & Very good \\
\hline Use of pesticides and fertilizers & Poor & Good & Very good \\
\hline
\end{tabular}

Source: Our elaboration, data collected direct survey.

Hypothesis Inclusive as an option to be shared (highlighting the social, landscape, and economic aspects), followed at a short distance by hypothesis Resilient (highlighting environmental, climate, landscape results) and, then, hypothesis City (with a more negative evaluation).

Then the equity matrix was developed. It provided stakeholders' opinions on the three hypotheses suggested. The selection of stakeholders was based on their potentialities to influence the targets of the project. They represent citizens, socially vulnerable groups, and different interested associations and possible users of the interventions, with different qualifications, both into the private and public. In particular, eight typologies of stakeholders were involved (as listed in Table 4). It is important to underline that stakeholders' opinions in the NAIADE model can only be of a quality kind: Language 
expressions from very poor, poor, medium, good, very good, and excellent (Table 4).These results show that a big number of the stakeholders and operator groups selected agreed with the evaluation of the three hypotheses.

Table 4. The equity matrix-Stakeholder opinions on the three hypotheses

\begin{tabular}{cccc}
\hline Typologies of Stakeholders & Scenario Inclusive & Scenario Resilient & Scenario City \\
\hline A1. Associations of citizens & Very good & Excellent & Poor \\
A2. Groups of pensioners & Excellent & Poor & Poor \\
A3. Cultural associations & Very good & Good & Good \\
A4. Playroom & Excellent & Very good & Good \\
A5. Trade unions & Very good & Excellent & Good \\
A6. Public Institutions & Good & Very good & Poor \\
A7. Scientific groups & Very good & Excellent & Poor \\
A8. Tertiary sector's companies & Excellent & Excellent & Good \\
\hline
\end{tabular}

Source: Our elaboration.

The results of the multi-criteria analysis highlighted that our hypothesis was inclusive and was the predominant hypothesis, followed closely by hypothesis Resilient, while hypothesis City gained a marginal meaning.

The results obtained through the equity analysis were used to examine possible alliances or conflicts among the opinions of stakeholders about the decision of what hypotheses to adopt. Besides agreeing on the classification of the different hypotheses, the results (Table 5) show that a high number of stakeholders were in agreement with hypothesis Inclusive.

Table 5. Classification of the scenarios corresponding to the higher consent (0.8423).

\begin{tabular}{lcccc}
\hline & Typologies of Stakeholders & Scenario Inclusive & Scenario Resilient & Scenario City \\
\hline A1 & Associations of citizens & 0.89 & 0.83 & 0.21 \\
A2 & Groups of pensioners & 0.83 & 0.59 & 0.12 \\
A3 & Cultural associations & 0.85 & 0.65 & 0.38 \\
A4 & Playrooms & 0.74 & 0.38 & 0.11 \\
A5 & Trade unions & 0.64 & 0.82 & 0.23 \\
A6 & Public Institutions & 0.36 & 0.29 & 0.28 \\
A7 & Scientific groups & 0.57 & 0.92 & 0.12 \\
A8 & Tertiary sector's companies & 0.86 & 0.85 & 0.54 \\
\hline
\end{tabular}

Source: Our elaboration, data collected direct survey.

The efficiency of this kind of approach relies on the possibility of establishing a "learning platform" that eases participation, information exchange, and reciprocal comprehension of participants, who stimulate each other towards a sharing of the territory. Results allowed the inclusion of several perspectives of the evaluation problem under study, as demonstrated by the different groups involved, increasing the perception of planners about the acceptability of the alternatives proposed that may lead to the improvement in strategic decisions and, therefore, create innovative ideas and new planning solutions based on the possibilities offered by the participated processes.

On the whole, the results obtained from this model of collaborative governance, eco-social-green, developed through the integration of a participative tool and a multi-criteria analysis, became strategic for the choices of urban green investments, in particular, related to climate change adaptation measures shared with the community.

\section{Conclusions}

In the last decade, literature has been enriched by a complex body of knowledge related to the evaluation of the benefits provided by GIs in an urban area to climate change mitigation and adaptation. 
Many pieces of research provide empirical evidence that can be used to design GIs to decrease the vulnerability of a city to climate change. In particular, the studies have shown the important role of GIs in contributing to climate change mitigation and offsetting urban carbon emissions (especially with the employment of green roofs and green facades); the thermal comfort due to the cooling effect of green roofs in different types of buildings and in different seasons and others important positive effects. However, the GIs can offer social and psychological benefits to citizens, especially socially vulnerable ones.

From the experiences mentioned and from the researches cited (only some for brevity and even synthetically) it could highlight that various GIs could provide multiple benefits in urban areas and this should be taken into account in the planning and design of the urban landscape. It is important to consider the multi-functionality of the GIs because the focus on a single advantage could, in turn, be harmful from another point of view (trade-off) [45].

It is necessary to replace the expansive building processes with the virtuous ones of urban regeneration, in which the GIs take on an increasingly important role for their functions of social inclusion, environmental protection, and in the mitigation and adaptation for climate change. Adaptation strategies need to preserve and enhance exiting GIs, and increase them where possible, especially taking opportunities in restructuring and new developments to create significant new spaces.

The provision of GIs has been widely recognized as playing an important role in meeting the challenge of climate change adaptation. Integration of GIs into more ecosystem-based spatial planning makes the design of GI assets a crucial planning tool for building more sustainable urban environments, resistant to future challenges and adaptable to future needs [46].

The GIs are well established in climate adaptation strategies, but it is important that these strategic tools are encouraged through specific integrated territorial and urban planning; long-term investments, planning, and sustainability in decision making; models of GIs for climate change adaptation and for optimal multiple benefits; evaluating both the economic and social and environmental benefits; encouraging citizen participation in the planning of GIs for climate adaptation $[4,42,43]$.

Due to the multifunctionality of GIs, there is no single science or reference discipline for its study [43]. They are based on the theories and practices of numerous scientific disciplines, such as conservation biology, landscape ecology, urban and regional planning, geographic analysis, information systems, and economists [69]. The research into GIs also needs to adjust to different spatial scales as its application can range from individual buildings to neighborhoods and cities to entire regions [70].

The expected impacts of climate change in urban settlements are very different: Impacts on health and quality of life (in particular of the weaker sections of the population), impacts on the buildings, on water, energy and transport infrastructures, on cultural heritage (due to landslides, floods and heatwaves), impacts on energy production and supply. Thus, to deal effectively with these impacts, we need the coordination of a very broad institutional network (multilevel governance) [43,71].

To date, however, the prospects for the development of the GIs are strictly dependent on its inclusion in planning policies, which local authorities and urban planning regulations must provide and support financially as well.

The ESs must be integrated into the planning and the choices of urban planning policies, making GIs and eco-innovation the fulcrum of an intelligent and sustainable urban transformation towards a new model of sustainable city enhancing biodiversity, environment and social inclusion [72].

The new guidelines on the protection of natural capital and biodiversity and attention to climate change are laying the foundations for outlining new ways of the government of the territory and the cities, with a proactive and engaging approach. Cities are ecosystems full of human presence, rich in knowledge and innovation, which welcome more than $50 \%$ of the world's population and about $70 \%$ of the Italian population. In cities, the conflict between artificiality and naturalness is maximum and causes loss of biodiversity, quality of ecosystem services, and resilience [73].

A direct consequence of the variety of expected impacts in urban settlements is the multiplicity of institutional actors who, together with citizens, must be involved in adaptation policies. Actors 
who will have a responsibility at different territorial scales (state, regions, provinces, municipalities) or responsibilities of certain sectors (basin authorities, energy service management bodies, water companies, etc.) and citizens, for which multilevel governance is required.

This research allowed us to point out that the methodological approach adopted, that was inspired by a model of city "eco-social-green" and based on the integration between the participated planning technique and the multi-criteria analysis, in the case of problems linked to the urban green spaces, represented a strategic tool.

The efficiency of this model of evaluation relies on the possibility of establishing a learning platform that facilitates the participation, information exchange, and reciprocal comprehension of the participants that support a strategy for the development and the fruition of the GIs of the city and to evaluate the perception of the importance of the GIs for climate change adaptation.

As other studies have already indicated [74-76], our study highlights an interesting potential for the wider use of SMCE in the governance of green spaces, for its ability to integrate ecological, social, and economic values, as well as the different stakeholder preferences among social groups, places, and temporal dynamics. Of course, policymakers have a broad ability to improve human well-being in cities through green space governance approaches that take into account their different components, economic, environmental, and social.

The value generated by the presence of GIs in the urban ecosystem, through the application of a vision of green-urban-planning, seems to be a valid instrument for achieving the objectives of realizing resilient and inclusive cities.

Author Contributions: All authors contributed to this work, in particular their individual contributions are: conceptualization L.S.; methodology L.S. and A.S.; validation and formal analysis A.S.; writing original draft and review and editing L.S. and A.S.

Acknowledgments: This work has been financed by the University of Catania within the project "Piano della Ricerca Dipartimentale 2016-2018 of the Department of Civil Engineering and Architecture".

Conflicts of Interest: The authors declare no conflict of interest.

\section{References}

1. Intergovernmental Panel on Climate Change (IPCC). Climate Change 2014; Contribution of Working Groups I, II and III to the Fifth Assessment Report of the Intergovernmental Panel on Climate Change; Core Writing Team, Pachauri, R.K., Meyer, L.A., Eds.; IPCC: Geneva, Switzerland, 2014; p. 151.

2. United Nations. Transforming our World: The 2030 Agenda for Sustainable Development; United Nations: New York, NY, USA, 2015.

3. United Nations. Revision of the World Urbanization Prospects; United Nations: New York, NY, USA, 2018.

4. Sturiale, L.; Scuderi, A. The evaluation of green investments in urban areas: A proposal of an eco-social-green model of the city. Sustainability 2018, 10, 4541. [CrossRef]

5. European Commission. The Forms and the Functions of the Green Infrastructures; European Commission/Envrinmental: Brussels, Belgium, 2016.

6. Environment Directorate-General for the Environment. Communication from the commission to the European Parliament, the Council, the European Economic and Social Committee and the Committee of the Regions Green Infrastructure (GI)—Enhancing Europe's Natural Capital; Environment Directorate-General for the Environment: Bruxelles, Belgium, 2013.

7. EU. 2009 WHITE PAPER Adapting to Climate Change: Towards a EUROPEAN Framework for Action; COM 2009 147/4; EU: Brussels, Belgium, 2009.

8. EEA. Green Infrastructure and Territorial Cohesion. The Concept of Green Infrastructure and its Integration into Policies Using Monitoring Systems; Technical Report no. 18/2011; European Environment Agency: Copenhagen, Denmark, 2011.

9. Werguin, A.C.; Duhem, B.; Lindholm, G.; Oppermann, B.; Pauleit, S.; Tjallingi, S. (Eds.) Green Structure and Urban Planning; Final Report, COST Action, No. C11; Office for Official Publications of the European Communities: Luxembourg, 2005. 
10. DG Environmental New Alerts Services. The Multifunctionality of the Green Infrastructures; In-Depth Report; DG Environmental New Alerts Services: Bruxelles, Belgium, 2012.

11. Munda, G. Multicriteria Evaluationina Fuzzy Environment-Theory and Applications. In Ecological Economics; Physica-Verlag: Heidelberg, Germany, 1995.

12. OECD. Competitive Cities and Climate Change; OECD: Milan, Italy, 2008.

13. World Bank. Cities and Climate Change: An Urgent Agenda; The World Bank: Washington, DC, USA, 2010.

14. UN-HABITAT. Cities and Climate Change: Global Report on Human Settlements 2011; United Nations Human Settlements Programme; Earthscan: London, UK; Washington, DC, USA, 2011.

15. COM. The European Strategy on Adaptation to Climate Change; European Commission: Brussels, Belgium, 2013; p. 216.

16. Monclús, J. From Park Systems and Green Belts to Green Infrastructures; Visions, U., Díez Medina, C., Monclús, J., Eds.; Springer: Cham, Germany, 2018.

17. Anguluri, R.; Narayanan, P. Role of green space in urban planning: Outlook towards smart cities. Urban. Urban Green. 2017, 25, 58-65. [CrossRef]

18. Jim, C.Y. Green spaces preservation and allocation for sustainable greening of compact cities. Cities 2004, 21, 311-320. [CrossRef]

19. Costanza, R. (Ed.) Ecological Economics: The Science and Management of Sustainability; Columbia University Press: New York, NY, USA, 1991.

20. Foster, J.; Lowe, A.; Winkelman, S. The Value of Green Infrastructures for Urban Climate Adaptation; Center for Clean Air Policy: Washington, DC, USA, 2011.

21. Brink, E.; Aalders, T.; Ádám, D.; Feller, R.; Henselek, Y.; Hoffmann, A.; Ibe, K.; Matthey-Doret, A.; Meyer, M.; Negrut, N.L.; et al. Cascades of green: A review of ecosystem based adaptation in urban areas. Glob. Environ. Chang. 2016, 36, 111-123. [CrossRef]

22. Hunt, A.; Watkiss, P. Climate change impacts and adaptation in cities: A review of the literature. Clim. Chang. 2011, 104, 13-49. [CrossRef]

23. Escobedo, F.J.; Kroeger, T.; Wagner, J.E. Urban forests and pollution mitigation: Analyzing ecosystem services and disservices. Environ. Pollut. 2011, 159, 2078-2087. [CrossRef] [PubMed]

24. Gómez-Baggethun, E.; Barton, D.N. Classifying and valuing ecosystem services for urban planning. Ecol. Econ. 2013, 86, 235-245. [CrossRef]

25. Economides, C. Green Infrastructure: Sustainable Solutions in 11 Cities across the United States; Columbia University Water: New York, NY, USA, 2014.

26. Nowak, D.J.; Crane, D.N.; Stevens, J.C. Air pollution removal by urban trees and shrubs in the United States. Urban For. Urban Green. 2006, 4, 115-123. [CrossRef]

27. Sturiale, L.; Timpanaro, G.; Foti, V.T.; Scuderi, A.; Stella, G. Social and Inclusive "Value" Generation in Metropolitan Area with the "Urban Gardens" Planning; Green Energy and Technology; Springer: Cham, Switzerland, 2019; in press.

28. Caspersen, O.H.; Olafsson, A.S. Recreational mapping and planning for enlargement of the green structure in greater Copenhagen. Urban Urban For. Green. 2010, 9, 101-112. [CrossRef]

29. Kabisch, N. Ecosystem service implementation and governance challenges in "urban green spaces" planning-the case of Berlin, Germany. Land Use Policy 2015, 42, 557-567. [CrossRef]

30. Jim, C.Y. Planning strategies to overcome constraints on greenspace provision in urban Hong Kong Town. Plan. Rev. 2002, 73, 127-152.

31. Yang, J.; Mcbride, J.; Zhou, J.; Sun, Z. The urban forest in Beijing and its role in air pollution reduction. Urban For. Urban Green. 2005, 3, 65-78. [CrossRef]

32. Wei, J.; Qian, J.; Tao, Y.; Hu, F.; Ou, W. Evaluating Spatial Priority of Urban Green Infrastructure for Urban Sustainability in Areas of Rapid Urbanization: A Case Study of Pukou in China. Sustainability 2018, 10, 327. [CrossRef]

33. Beckett, K.P.; Freer-Smith, P.; Taylor, G. Urban woodlands: their role in reducing the effects of particulate pollution. Environ. Pollut. 1998, 99, 347-360. [CrossRef]

34. Nowak, D.J.; Mchale, P.J.; Ibarra, M.; Crane, D.; Stevens, D.J.; Luley, C.J. Modeling the Effects of Urban Vegetation on Air Pollution. In Air Pollution Modeling and Its Application XII; Plenum Press: New York, NY, USA, 1998; pp. 399-407. 
35. Saunders, S.; Dade, E.; Van Niel, K. An Urban Forest Effects (UFORE) model study of the integrated effects of vegetation on local air pollution in the Western Suburbs of Perth WA. In Proceedings of the 19th International Congress on Modelling and Simulation, Cambridge, UK, 30 March-1 April 2011; pp. 1824-1830.

36. Baró, F.; Chaparro, L.; Gómez-Baggethun, E.; Langemeyer, J.; Nowak, D.J.; Terradas, J. Contribution of ecosystem services to air quality and climate change mitigation policies: the case of urban forests in Barcelona, Spain. Ambio 2014, 43, 466-479. [CrossRef]

37. Akbari, H.; Pomerantz, M.; Taha, H. Cool surfaces and shade trees to reduce energy use and improve air quality in urban areas. Sol. Energy 2001, 70, 295-310. [CrossRef]

38. Tzoulas, K.; Korpela, K.; Venn, S.; Yli-Pelkonen, V.; Kaźmierczak, A.; Niemela, J.; James, P. Promoting ecosystem and human health in urban areas using green infrastructure: a literature review. Landsc. Urban Plann. 2007, 81, 167-178. [CrossRef]

39. Jayasooriya, V.M.; Muthukumaran, A.W.M.N.G.S.; Perera, B.J.C. Green infrastructure practices for improvement of urban air quality. Urban For. Urban Green. 2017, 21, 34-47. [CrossRef]

40. Gill, S.E.; Handley, J.F.; Ennos, A.R.; Pauleit, S. Adapting Cities for Climate Change: The Role of the Green Infrastructure. Built Environ. 2007, 1, 115-133. [CrossRef]

41. Radovanović, M.; Lior, N. Sustainable economic-environmental planning in Southeast Europe-Beyond-GDP and climate change emphases. Sustain. Dev. 2017, 25, 580-594. [CrossRef]

42. Breuste, J.; Artmann, M.; Li, J.X.; Xie, M.M. Special issue on green infrastructure for urban sustainability. J. Urban Plan. Dev. 2015, 141. [CrossRef]

43. Scuderi, A.; Sturiale, L. Evaluations of Social Media Strategy for Green Urban planning in Metropolitan Cities; Smart Innovation, Systems and Technologies; Springer International Publishing AG, part of Springer Nature: New York, NY, USA, 2019; pp. 76-84.

44. Benedict, M.A.; McMahon, E.T. Green Infrastructure: Smart Conservation for the 21st Century. Renew. Resour. J. 2002, 20, 12-17.

45. Demuzerea, M.; Orrubc, K.; Heidrichd, O.; Olazabalej, E.; Genelettif, D.; Orrugh, H.; Bhavei, A.G.; Mittali, N.; Feliue, E. Mitigating and adapting to climate change: Multi-functional and multi-scale assessment of green urban infrastructure. J. Environ. Manag. 2014, 146, 107-115. [CrossRef] [PubMed]

46. Simonis, U.E. Greening urban development: on climate change and climate policy. Int. J. Soc. Econ. 2011, 11, 919-928. [CrossRef]

47. IPCC. Fifth Assessment Report: Climate Change 2014: Mitigation of Climate Change; IPCC: Geneva, Switzerland, 2014.

48. Morancho, A.B. A hedonic valuation of urban green areas. Landsc. Urban Plan. 2003, 66, 35-41. [CrossRef]

49. Haaland, C.; van den Bosch, C.K. Challenges and strategies for urban green-space planning in cities undergoing densifification: A review. Urban. Urban For. Green. 2015, 14, 760-771. [CrossRef]

50. Miccoli, S.; Finucci, F.; Murro, R. Social evaluation approaches in landscape projects. Sustainability 2014, 6, 7906-7920. [CrossRef]

51. Lo, A.Y.; Jim, C.Y. Willingness of residents to pay and motives for conservation of urban green spaces in the compact city of Hong Kong. Urban. Urban Green. 2010, 9, 113-120. [CrossRef]

52. Maloutas, T.; Pantelidou, M. Debatsanddevelopments: The glassmenagerieofurbangovernanceandsocial cohesion concepts and stake/concepts as stakes. Int. J. Urban Reg. Res. 2004, 28, 449-465. [CrossRef]

53. Niemelä, J.; Saarela, S.-R.; Tarja Söderman, T.; Kopperoinen, L.; Yli-Pelkonen, V.; Väre, S.; Kotze, D.J. Using the ecosystem services approach for betterplanning and conservation of urban green spaces: A Finland case study. Biodivers. Conserv. 2010, 19, 3225-3243. [CrossRef]

54. Soderberg, H.; Karman, E. MIKA: Methodologiesfor Integrationof Knowledge Areas-The Caseof Sustainable Urban Water Management; Department of Built Environment \& Sustainable Development, Chalmers Architecture, Chalmers University of Technology: Goeteborg, Sweden, 2003.

55. Panell, D.J.; Glenn, N.A. A framework for the economic evaluation and selection of sustainability indicators in agriculture. Ecol. Econ. 2000, 33, 135-149. [CrossRef]

56. Siciliano, G. Social multicriteria evaluation of farming practices in the presence of soil degradation. A case study in Southern Tuscany, Italy. Environ. Dev. Sustain. 2009, 11, 1107-1133. [CrossRef]

57. Vargas Isaza, O.L. La evaluación multicriterio social y su aporte a la conservación de los bosques social multicriteria. Rev. Fac. Nac. De Agron. Medellín 2005, 58, 2665-2683. 
58. De Marchi, B.; Funtowicz, S.O.; Lo Cascio, S.; Munda, G. Combining participative and institutional approacheswith multicriteria evaluation. An empirical study for water issues in Troina, Sicily. Ecol. Econ. 2000, 34, 267-282. [CrossRef]

59. Greco, S.; Matarazzo, B.; Slowinski, R. Dominance based Rough Set Approach to decision under uncertainty and time preference. Ann. Oper. Res. 2010, 176, 41-75. [CrossRef]

60. Munaretto, S.; Siciliano, G.; Turvani, M. Integrating adaptive governance and participatory multicriteria methods: A framework for climate adaptation governance. Ecol. Soc. 2014, 19, 74. [CrossRef]

61. Scuderi, A.; Sturiale, L. Multi-criteria evaluation model to face phytosanitary emergencies: The case of citrus fruits farming in Italy. Agric. Econ. 2016, 62, 205-214. [CrossRef]

62. Munda, G. Social Multicriteria Evaluation for a Sustainable Economy; Springer: Berlin, Germany, 2008.

63. Munda, G. A NAIADE based Approach for Sustainability Benchmarking. Int. J. Environ. Technol. Manag. 2006, 6, 65-78. [CrossRef]

64. Shmelev, E.S.; Rodriguez-Labajos, B. Dynamic multidimensional assessment of sustainability at the macro level: The case of Austria. Ecol. Econ. 2009, 68, 2560-2573. [CrossRef]

65. Torrieri, F.; Concilio, G.; Nijkamp, P. Decision support tools for urban contingency policy. A scenario approach to risk management of the Vesuvio area in Naples-Italy. J. Conting. Crisis Manag. 2002, 10, 95-112. [CrossRef]

66. Tiwari, A.P. Choice and Preference of Water Supply Institutions-An Exploratory Study of Stakeholders' Preferences of Water Sector Reform in Metro City of Delhi, India. 2007. Available online: http://agua.isf.es/ semana\%E2\%80\%A6/Doc7_APTiwari_2pag_xcra_a_dobre\%20cara.pdf (accessed on 24 May 2019).

67. Bekessy, S.A.; White, M.; Gordon, A.; Moilanen, A.; Mccarthy, M.A.; Wintle, B.A. Transparent planning for biodiversity and development in the urban fringe. Landsc. Urban Plan. 2012, 108, 140-149. [CrossRef]

68. Voogd, H. Multiple Criteria Evaluation for Urban and Regional Planning; Lion: London, UK, 1983.

69. European Commission. The Multifuntionality of Green Infrastructures; Science for Environment Policy/In-depth Reports; European Commission: Bruxelles, Belgium, 2012.

70. Naumann, S.; Davis, M.; Kaphengst, T.; Pieterse, M.; Rayment, M. Design, Implementation and Cost Elements of Green Infrastructure Projects; Final report; European Commission: Brussels, Belgium, 2011.

71. Matthews, T.; YLob, A.; AByrnec, J. Reconceptualizing green infrastructure for climate change adaptation: Barriers to adoption and drivers for uptake by spatial planners. Landsc. Urban Plan. 2015, 138, 155-163. [CrossRef]

72. Foti, V.T.; Scuderi, A.; Stella, G.; Sturiale, L.; Timpanaro, G.; Trovato, M.R. The integration of agriculture in the politics of social regeneration of degraded urban areas. In Integrated Evaluation for the Management of Contemporary Cities; Mondini, G., Fattinnanzi, E., Oppio, A., Bottero, M., Stanghellini, S., Eds.; Results of SIEV, Green Energy and Technology; Springer: Cham, Switzerland, 2018; pp. 99-111.

73. Forest Research. Benefifits of Green Infrastructures; Report by Forest Research; Forest Research: Farnham, UK, 2010.

74. Langemeyerab, J.; Gómez-Baggethuncf, E.; Haasede, D.; Scheuerd, S.; Elmqvistb, T. Bridging the gap between ecosystem service assessments and land-use planning through Multi-Criteria Decision Analysis (MCDA). Environ. Sci. Policy 2016, 62, 45-56. [CrossRef]

75. Srdjevic, Z.; Lakicevic, M.; Srdjevic, B. Approach of decision making based on the analytic hierarchy process for urban landscape management. Environ. Manag. 2013, 51, 777-785. [CrossRef]

76. Grêt-Regamey, A.; Celio, E.; Klein, T.M.; Wissen Hayek, U. Understanding ESs trade-offs with interactive procedural modeling for sustainable urban planning. Landsc. Urban Plan. 2013, 109, 107-111. [CrossRef]

(C) 2019 by the authors. Licensee MDPI, Basel, Switzerland. This article is an open access article distributed under the terms and conditions of the Creative Commons Attribution (CC BY) license (http://creativecommons.org/licenses/by/4.0/). 